\title{
Ecology of Wahlberg's velvet gecko, Homopholis wahlbergii, in southern Africa
}

\author{
${ }^{\S}$ Martin J. Whiting ${ }^{1 *}$, Leeann T. Reaney ${ }^{\dagger}$ \& J. Scott Keogh ${ }^{2^{\ddagger}}$ \\ ${ }^{1}$ School of Animal, Plant and Environmental Sciences, University of the Witwatersrand, Private Bag 3 , \\ WITS, 2050 South Africa. \\ ${ }^{2}$ School of Botany and Zoology, The Australian National University, Canberra, ACT, 0200, Australia \\ Received 9 January 2006. Accepted 20 May 2006
}

\begin{abstract}
We examined 170 museum specimens of the southern African gekkonid lizard Homopholis wahlbergii, to quantify sexual dimorphism, male and female reproductive cycles and diet. The largest male and female we recorded were 116 and $119 \mathrm{~mm}$ snout-vent length (SVL) respectively. We compared SVL, tail length, head length, head width and eye diameter and found no evidence of sexual dimorphism in any of these characters. The smallest female with thickened muscular oviducts and follicles, indicating sexual maturity, was $59 \mathrm{~mm}$ SVL, but the smallest female we found with fully developed eggs was $85 \mathrm{~mm}$ SVL. Virtually all females larger than $59 \mathrm{~mm}$ appeared to be in some stage of reproduction, suggesting that females reproduce every year once they reach sexual maturity. Egg size ranged from 17-19 mm long. Egg size was not correlated with maternal SVL. We found adult females with ready-to-lay eggs during the warmer months of the year, but not during winter and spring. The smallest sexually mature male was $72 \mathrm{~mm}$ SVL. Virtually all males larger than this size displayed at least semi-turgid testes and most adult male testes were at least semi-turgid for much of the year. The only significant decrease in testicular activity was in mid-winter (June-August), thus, spermatogenesis is closely tied to female follicular development and ovulation. Velvet geckos are largely insectivorous $(92 \%)$ and feed on a broad spectrum of prey. Their diet was dominated both numerically (34\%) and volumetrically (22\%) by beetles. Lepidoptera were the next most important prey category, suggesting that they exploit both terrestrial and flying invertebrates. They are unusual among lizards because they feed on millipedes. Males and females had very similar diets which may be explained by their lack of sexual dimorphism, although females tended to eat a greater volume of prey. Interestingly, less than half $(37 \%)$ of the lizards examined contained prey items, suggesting that most individuals were not in positive energy balance. We also found evidence of prey size selection as a function of gape size, such that larger geckos took advantage of larger prey items.
\end{abstract}

Key words: lizard, life history, sexual size dimorphism, diet, reproduction.

\section{INTRODUCTION}

Developing life history theory requires an understanding of broad-scale patterns in the ecology of a multitude of living organisms. Lizards have repeatedly demonstrated their utility as models for uncovering patterns in life history strategies (e.g. Pianka 1986; Pianka \& Vitt 2003; Vitt et al. 2003) because compared to many other vertebrates they are often locally abundant, intact prey items are easily recovered from their stomachs, and they are readily observed. Squamate reptiles are however, an extremely diverse group (c. 4330 species of lizards excluding snakes; Vitt et al. 2003) with a global distribution. We still have only a

\footnotetext{
${ }^{\S}$ Order of authorship determined by the toss of a coin.

*Author for correspondence. E-mail: martin@gecko.wits.ac.za

${ }^{\dagger}$ Present address: School of Botany and Zoology, The Australian National University, Canberra, ACT, 0200, Australia.

E-mail: leeann.reaney@anu.edu

”E-mail: scott.keogh@anu.edu
}

rudimentary understanding of ecology and life history of many species and to fill these gaps, we need to sample taxa from multiple clades and from geographically disparate areas. Geckos (Gekkonidae) have been relatively intensively studied, but there is a bias towards specific taxa and geographic areas. Southern Africa has one of the most diverse gecko faunas per unit area in the world (Branch 1998), and occupy a wide range of habitat types and niches. Much of our understanding of gecko ecology is from early work by Pianka and colleagues (summarized in Pianka 1986), who conducted intensive field studies of several species of desert geckos in the Kalahari (see also Hibbitts et al. 2005). Of these, most are terrestrial species, although some do make use of trees (e.g. Lygodactylus capensis, Pachydactylus spp., Pianka 1986: 162-163). However, the ecology of any of the arboreal African geckos, particularly 
from mesic savanna, is largely unknown.

The African 'velvet' geckos of the genus Homopholis comprise four species of mediumsized to large arboreal lizards that are well known for their soft skin. Homopholis boivini is endemic to Madagascar and H. fasciata is found in east Africa. The other two species are endemic to southern Africa. Homopholis mulleri has a very restricted distribution between the Soutpansberg mountain range and the Limpopo River in the Limpopo Province of South Africa, while $H$. wahlbergii has a broad distribution over Zimbabwe, eastern Botswana, southern Mozambique, Zululand, and the Limpopo Province of South Africa (Branch 1998). Very little is known about the ecology of any of the four species, but $H$. wahlbergii is well represented in museum collections because it is locally common and widely distributed. This species shelters in a range of habitats including under tree bark, in tree holes, rock overhangs and even empty bird nests (Branch 1998). Homopholis wahlbergii are nocturnal, but are sometimes seen during the day, particularly when making short excursions from their refuge. There are currently no quantitative data on sexual dimorphism, reproductive cycles, or diet composition.

We studied the ecology of Wahlberg's velvet gecko, Homopholis wahlbergii, by dissecting museum specimens. We had three main objectives: to test for sexual size dimorphism, to examine diet, and to quantify male and female reproductive ecology.

\section{MATERIALS \& METHODS}

\section{Morphology and reproduction}

We examined 170 museum specimens from the Transvaal Museum (Pretoria) in South Africa. We made a mid-ventral incision to expose the gonads in order to score sex and reproductive condition. Males were recorded as sexually mature if testes were thick (as opposed to flat and ribbon-like in immature males), and sexually active at the time of preservation if testes were turgid and/or the efferent ducts were opaque due to the presence of sperm. Females were recorded as sexually mature if the oviducts appeared muscular, and sexually active at the time of preservation if large ovarian follicles or eggs were present. The diameter of the largest follicle or egg was recorded. For each specimen we also recorded the following morphological variables to examine sexual size dimorphism: snout-vent length (SVL), tail length (excluding individuals with broken tails), head length, head width at the widest point and eye diameter. SVL and tail length were measured with a plastic ruler to the nearest $0.01 \mathrm{~mm}$ while remaining morphological measurements were made to the nearest $0.01 \mathrm{~mm}$ using digital calipers. Body size variables were log-transformed prior to analyses to meet the assumptions of parametric statistics. We used two sample, two-tailed $t$-tests and analysis of covariance (ANCOVA) to test for sexual size dimorphism and regression analysis to examine correlations between maternal body size and egg size.

\section{Diet}

We determined diet by examining the stomach contents of preserved specimens. Prey were spread out in a Petri dish and generally identified to Order and the length and width of all intact prey items were measured to the nearest $0.01 \mathrm{~mm}$ using digital callipers. Prey volume was calculated using the formula for a prolate spheroid (Vitt et al. 1993; Vitt \& Zani 2005),

$$
\text { volume }=4 / 3 p(\text { length } / 2)^{*}(\text { width } / 2)^{2} .
$$

We estimated niche breadth using the reciprocal of Simpson's (1949) diversity measure:

$$
\beta=1 / \sum_{i=1}^{n} p_{i}^{2},
$$

where $i=$ resource category, $p=$ proportion of resource category $i$, and $n=$ total number of categories. Values vary from 1 (exclusive use of 1 prey type) to $n$ (even use of all prey types). Prey categories were the arthropod orders of prey items found in the gut contents (Table 2). All means are reported \pm 1 S.E. Differences were considered significant when alpha was $<0.05$.

\section{RESULTS}

\section{Morphology}

The largest male and female we recorded were 116 and $119 \mathrm{~mm}$ SVL respectively. The smallest specimen measured had a SVL of $34 \mathrm{~mm}$. Mean values for adult SVL, tail length, head length, head width, and eye diameter show no significant sexual size dimorphism in any of the measured traits based on mean values alone (Table 1). The result was unchanged when we controlled for differences in body size. Using ANCOVA (SVL as covariate), the sexes were not significantly different in tail length (slopes homogeneous $F_{1,106}=$ $0.273, P=0.602$; intercepts $F_{1,107}=0.073, P=$ 
Table 1. Summary of sexual size dimorphism in morphological traits in Homopholis wahlbergii from southern Africa. The last three columns show results from unpaired two-tailed $t$-tests for sexual size dimorphism. Statistical tests were performed on natural log-transformed data.

\begin{tabular}{|c|c|c|c|c|c|c|c|c|c|}
\hline \multirow[b]{2}{*}{ Trait (mm) } & \multicolumn{3}{|c|}{ Adult male } & \multicolumn{3}{|c|}{ Adult female } & \multirow[b]{2}{*}{ d.f. } & \multirow[b]{2}{*}{$t$} & \multirow[b]{2}{*}{$P$} \\
\hline & $n$ & Mean \pm S.E. & Range & $n$ & Mean \pm S.E. & Range & & & \\
\hline Snout-vent length & 59 & $92.31 \pm 1.39$ & $72-116$ & 77 & $94.57 \pm 1.27$ & $71-119$ & 134 & 1.18 & 0.2403 \\
\hline Tail length & 36 & $71.86 \pm 2.23$ & $36-96$ & 49 & $72.59 \pm 1.73$ & $42-94$ & 83 & 0.26 & 0.7931 \\
\hline Head length & 59 & $25.28 \pm 0.43$ & $19-32$ & 77 & $25.50 \pm 0.33$ & $19-33$ & 134 & 0.52 & 0.6071 \\
\hline Head width & 59 & $18.77 \pm 0.31$ & 13-25 & 77 & $18.92 \pm 0.26$ & $14-24$ & 134 & 0.40 & 0.6913 \\
\hline Eye diameter & 59 & $5.09 \pm 0.09$ & $3.50-6.50$ & 77 & $5.21 \pm 0.07$ & $3.5-6.50$ & 134 & 1.26 & 0.2083 \\
\hline
\end{tabular}

0.787), head length (slopes homogeneous $F_{1,160}=$ 1.991, $P=0.160$; intercepts $F_{1,161}=0.934, P=$ 0.335 ), head width (slopes homogeneous $F_{1,160}=$ $2.085, P=0.151$; intercepts $F_{1,161}=0.832, P=0.363$ ) and using head length as the covariate, eye diameter was not significantly different between the sexes (slopes homogeneous $F_{1,160}=0.480, P=$ 0.489 ; intercepts $\left.F_{1,161}=2.258, P=0.135\right)$.

\section{Reproduction}

The smallest reproductively mature female was only $59 \mathrm{~mm}$ SVL. However, the smallest female we found with fully developed eggs was $85 \mathrm{~mm}$ SVL. Virtually all females larger than $59 \mathrm{~mm}$ appeared to be in some stage of reproduction, either with developing follicles or eggs, suggesting that females reproduce every year once they reach sexual maturity. Like most geckos, Homopholis wahlbergii has a fixed clutch size of two eggs. The size of fully developed (shelled) eggs ranged from 17-19 $\mathrm{mm}$ long but we did find one female with $19 \mathrm{~mm}$ eggs that were still unshelled (Fig. 1). Based on 12 females we found with fully developed eggs, egg size did not appear to be correlated with maternal SVL $(r=0.013, n=12, P=0.969)$. A plot of ovarian follicle or egg diameter against the month of capture revealed that ovarian follicles were less than $10 \mathrm{~mm}$ throughout winter but vitellogenic follicles or fully shelled eggs were found throughout the rest of the year (NovemberJune, Fig. 1). Therefore, females appear to lay eggs for all of the warm months of the year.

The smallest mature male was $72 \mathrm{~mm}$ SVL. Virtually all males larger than this size displayed semi-turgid or turgid testes (Fig. 2a). In most adult males, testes were at least semi-turgid for much of the year, with visibly opaque efferent ducts (indicating the presence of sperm) in many cases. The only significant decrease in testicular activity was in mid-winter (June-August; Fig. 2b). Thus,

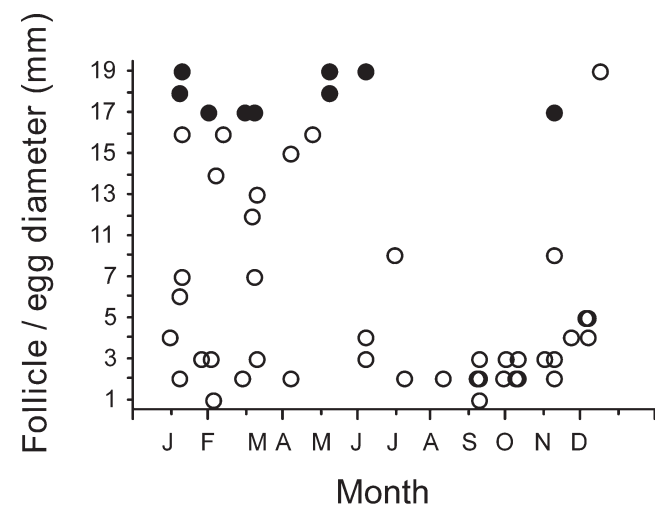

Fig. 1. Reproductive biology of female Homopholis wahlbergii relative to time of year. Open circles represent unshelled ovarian follicles and closed circles represent fully shelled eggs.

spermatogenesis coincides with female follicular development and ovulation. The frequency of gecko body sizes relative to sexual maturity and mean adult body size is shown in Fig. 3 .

\section{Diet}

We identified 11 prey categories (Table 2). Of the 170 lizards (including lizards that contained unidentifiable prey) we examined, 64 (37\%) contained 159 food items. All food items, with the exception of shed skins, were arthropods and the majority $(92.1 \%)$ of identifiable prey were insects (Table 2). Beetles (Coleoptera) dominated the diet numerically, were also the most important prey item by volume, and were also found in more individual lizards $(38.4 \%)$ than any other prey category. Adult Lepidoptera and Isoptera (termites) were of approximately equal value and followed beetles as the next most important prey category by both number and volume, although the percentage of lizards containing adult Lepidoptera was slightly higher than the Isoptera. Termites 


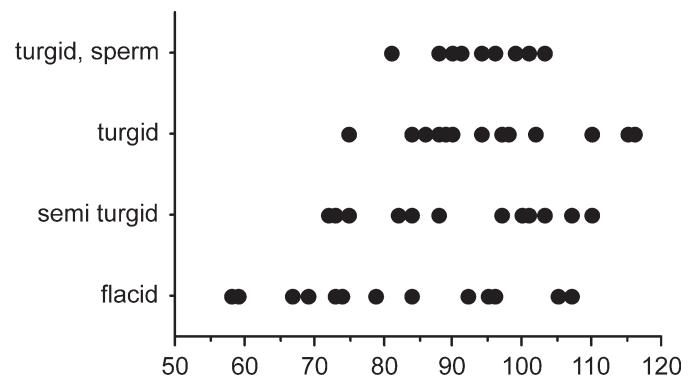

A)

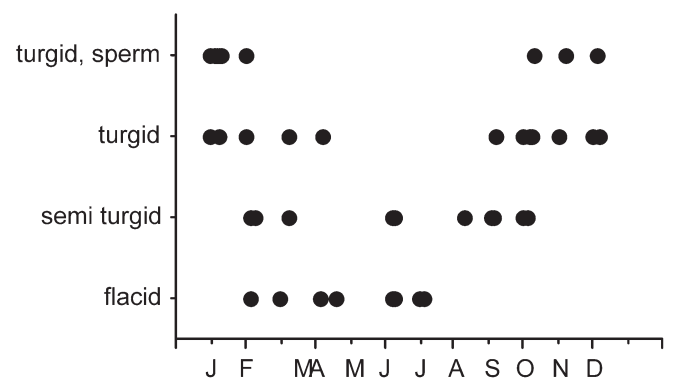

B)

Month

Fig. 2. Reproductive biology of male Homopholis wahlbergii relative to $(\mathbf{A}) \mathrm{SVL}$ and $(\mathbf{B})$ time of year. A shows that most males $>72 \mathrm{~mm}$ SVL had at least semi-turgid testes, indicating sexual maturity. B shows that males appear to have at least semi-turgid testes during all of the warmer months and this coincides with the female reproductive cycle.

may represent somewhat of a bias because a few lizards $(n=5)$ ate large quantities of termites. Orthopterans were also eaten by relatively few lizards (c. 12\%), but represent a significant prey volume.

Mean prey length was $11.76 \pm 0.49(3-27.88)$ $\mathrm{mm}$, while prey width was $4.76 \pm 0.18(1.39-9.95)$ $\mathrm{mm}$, and prey volume was $179.44 \pm 16.92(4.78-$ $793.14) \mathrm{mm}^{3}$. On average, prey were mediumsized but did include large prey items such as millipedes and certain Orthoptera (Table 2).

Lizard SVL was significantly positively correlated with prey volume $(n=42, r=0.44, P=$ $0.0035)$, but not the number of prey an individual lizard consumed ( $n=42, r=0.25, P=0.1105)$. Lizard gape size was also significantly positively correlated with the largest prey item $(n=39, r=$ $0.45, P=0.004$; Fig. 4), but not the number of prey an individual lizard consumed $(n=42, r=0.22$, $P=0.1699)$. Males and females ate similar numbers of prey categories $\chi^{2}{ }_{5}=6.55, P=0.26$ ). Furthermore, males and females had similar niche

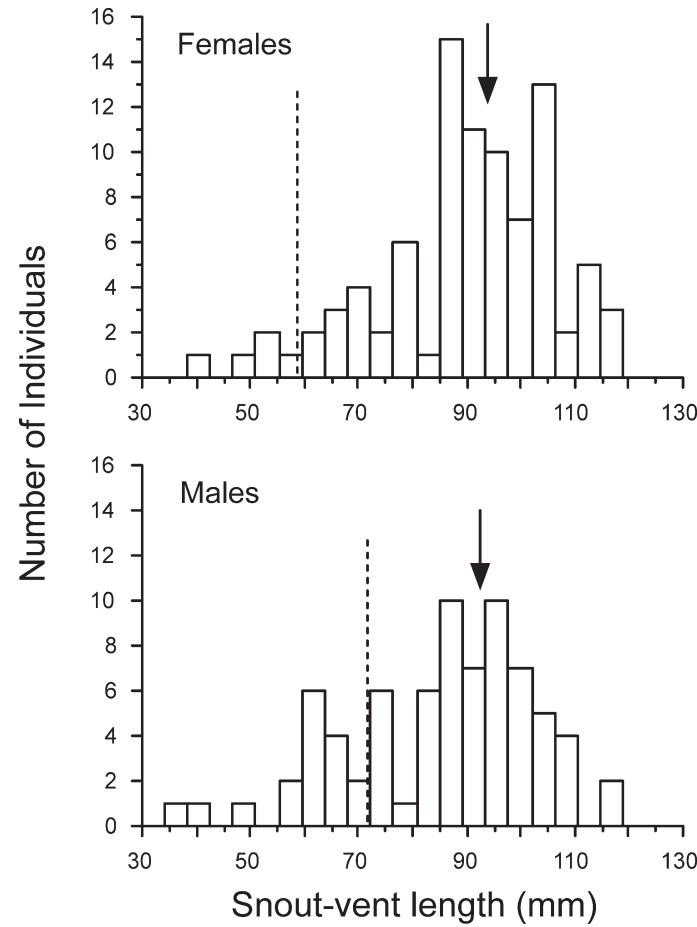

Fig. 3. Frequency distribution of SVL of female and male Homopholis wahlbergii examined in this study. Dashed lines indicate the smallest SVL at sexual maturity and arrows indicate mean SVLs of adults only. See Table 1 for statistical comparisons of mean values.

breadths for both prey frequency (male mean: 1.5 \pm 0.22 , female mean: $1.55 \pm 0.21 ; t_{37}=-0.15, P=$ 0.89 ) and prey volume (male mean: $1.31 \pm 0.2$, female mean: $1.35 \pm 0.16$; $t_{27}=-0.14, P=0.886$ ). However, males and females ate significantly different volumes of prey $\chi^{2}{ }_{5}=1018.6, P<0.0001$; Fig. 5). When SVL was controlled for, females consumed significantly greater prey volume than males (male mean: $477.53 \pm 116.37 \mathrm{~mm}^{3}$, female mean: $501.39 \pm 83.91 \mathrm{~mm}^{3}$; ANCOVA, $F_{1,39}=9.5$, $P=0.004)$, but the number of arthropods consumed was independent of sex (male mean: $3.58 \pm$ 0.67 , female mean: $2.78 \pm 0.49$; ANCOVA, $F_{1,39}=$ $3.4, P=0.073)$.

\section{DISCUSSION}

Sexual size dimorphism in lizards can evolve for a wide range of reasons, including male contest competition (males are the larger sex) or fecundity selection (females are the larger sex; Shine 1989; Olsson et al. 2002). Gekkonid lizards as a group display the full range of sex-biased dimorphism including species that display no bias to others that display strongly biased dimorphism. Overall, 
Table 2. Summary of the diet of 61 Homopholis wahlbergii from southern Africa. Insect prey were identified to order. $N$ represents the number of insect prey recovered from stomachs and the associated percentage; volume was calculated using the formula for a prolate spheroid (see text) and reported by invertebrate category; and frequency refers to the number of lizards containing a particular prey item. Three additional lizards each contained a shed skin, which have not been included in calculations in this table. There were also 16 unidentifiable prey items in 15 lizards, comprising a volume of $565.27 \mathrm{~mm}^{3}$, which are not included in calculations below.

\begin{tabular}{lrrrrrr}
\hline Prey type & $n$ & $\% N$ & Volume $\left(\mathrm{mm}^{3}\right)$ & $\%$ Volume & Frequency & \% Frequency \\
\hline Orthoptera & 11 & 7.86 & 2866.62 & 14.24 & 9 & 12.33 \\
Coleoptera & 47 & 33.57 & 4516.84 & 22.43 & 28 & 38.36 \\
Lepidoptera (adults) & 21 & 15.00 & 4361.14 & 21.66 & 8 & 10.96 \\
Lepidoptera (larvae) & 11 & 7.86 & 786.75 & 3.91 & 6 & 8.22 \\
Hemiptera & 1 & 0.71 & 40.54 & 0.2 & 1 & 1.37 \\
Hymenoptera & 4 & 2.86 & 41.62 & 0.21 & 3 & 4.11 \\
Diptera & 7 & 5.00 & 217.15 & 1.08 & 3 & 4.11 \\
Isoptera & 27 & 19.29 & 4412.73 & 21.92 & 5 & 6.85 \\
Diplopoda & 6 & 4.29 & 2160.12 & 10.73 & 6 & 8.22 \\
Chilopoda & 1 & 0.71 & 42.58 & 0.21 & 1 & 3 \\
Spiders & 4 & 2.86 & 688.64 & 3.42 & 3.37 \\
TOTAL & 140 & 100.00 & 20134.73 & 100.00 & 73 & 4.11 \\
Niche breadths & & 5.24 & & 5.56 & & 100.00 \\
\hline
\end{tabular}

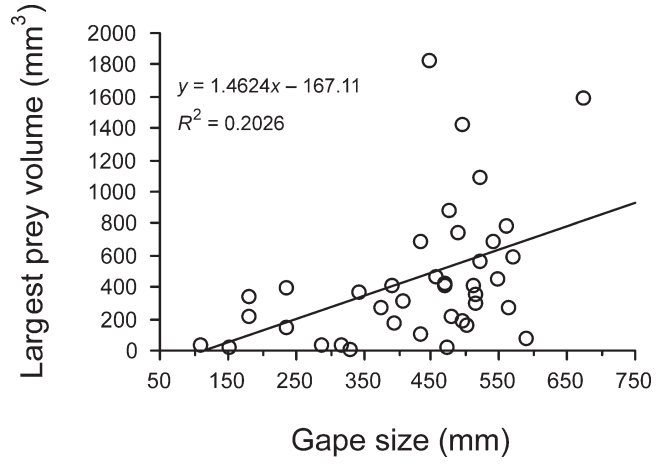

Fig. 4. The relationship between gape size (head length $\times$ head width) and volume for the largest individual prey item in the gecko Homopholis wahlbergi. The fitted trend line is logarithmic.

female biased sexual size dimorphism is most common in geckos (Fitch 1981). We found a complete absence of sexual size dimorphism in $H$. wahlbergii in any of the traits that we measured. Given that most geckos have a fixed clutch size of two and that we found no evidence of any relationship between egg size and maternal size, fecundity selection is unlikely. Based on the lack of dimorphism, we also speculate that $H$. wahlbergii probably displays comparatively little male-male competition, although field observations and/or laboratory trials are required to test this.

Both sexes appear to attain sexual maturity at comparatively small sizes $(59 \mathrm{~mm}$ for females,
$72 \mathrm{~mm}$ for males). While we found very small females with developing follicles, the smallest female we found with fully developed eggs was $85 \mathrm{~mm}$, so it is possible that females do not reach full maturity until they are significantly larger than $59 \mathrm{~mm}$. We found females with fully developed ready-to-lay eggs throughout all the warmer months of the year. While we were not able to determine if individual females lay multiple clutches in a season, the temporal distribution of fully developed eggs raises the possibility that they are laying multiple clutches. Our data on male reproductive cycles is also suggestive of this because males were found with highly turgid testes during all the warmer months. Males appear to commence spermatogenesis one to two months earlier in spring (September-October) than females commence vitellogenesis (November). The smallest lizards we observed were $34 \mathrm{~mm} \mathrm{SVL}$ and individuals of this size were found in both January and May. This can be explained by one of two scenarios: either females are layingy multiple clutches or certain females reproduce later, possibly because they were born later and therefore matured later.

Branch (1998) suggested that $H$. wahlbergii feeds on large insects, particularly grasshoppers and cockroaches, but that it also eats termites and millipedes. We found that $H$. wahlbergii was largely insectivorous, but that the diet was dominated by beetles. Prey volume was a function of body size 
A

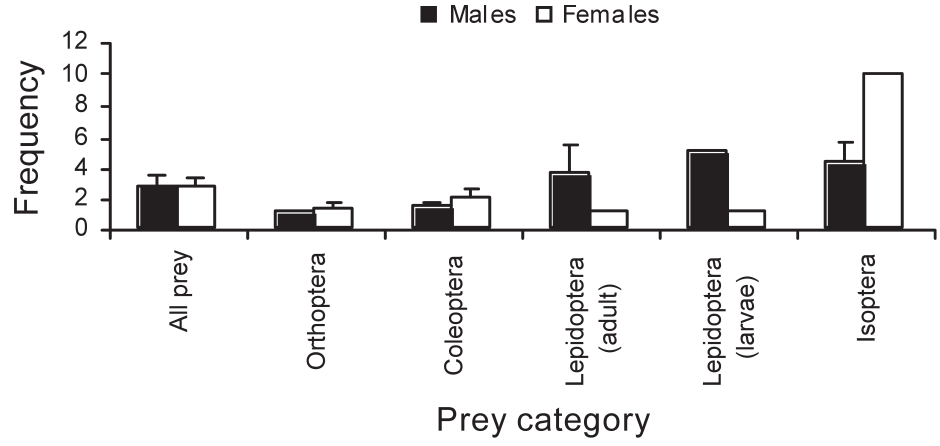

B

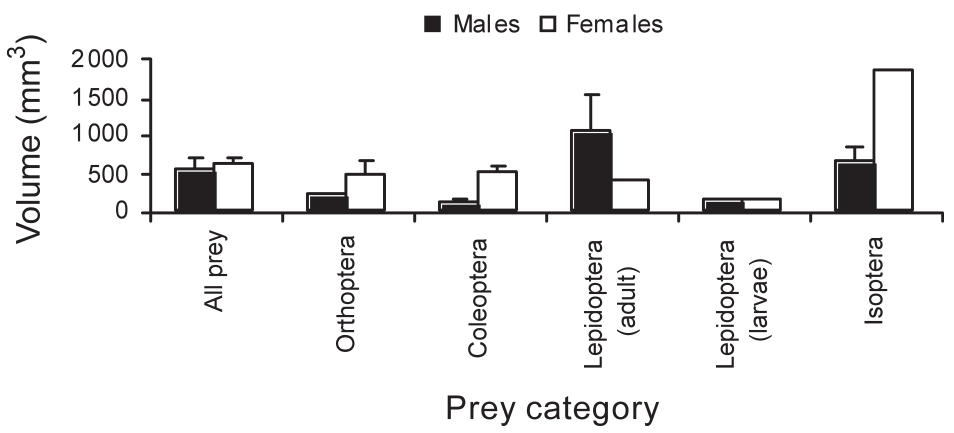

Fig. 5. Mean ( \pm 1 S.E.) prey selection by male and female Homopholis wahlbergii by $(\mathbf{A})$ number and $(\mathbf{B})$ volume.

such that larger lizards ate prey of greater volume. Because of the expected link between body and gape size, lizards with larger heads ate larger prey. The number of prey an individual lizard ingested appeared to be unrelated to body size, but this may be because most lizards contained relatively few prey items. Interestingly, a relatively low number of lizards $(37 \%)$ contained prey in their stomachs, suggesting that they may eat less frequently than many other lizard species. Huey et al. (2001) examined an extensive data set of 18223 individuals representing 127 species from four continents and found that most individuals (86.8\%) were in positive energy balance (i.e. stomachs contained food). However, they did note that nocturnal lizards had a higher frequency of empty stomachs compared to diurnal lizards and that this relationship still held when nocturnal and diurnal geckos were compared (24.1 vs $10.5 \%$ ). In comparison, the proportion of velvet geckos with empty stomachs was much higher $(63 \%)$ and suggests an intriguing result that may warrant further investigation. Alternatively, this may be an artefact of how long lizards were maintained alive (without feeding) before being preserved.

Although we did not study lizards in the field, their diet suggests that they are able to exploit both terrestrial (e.g. millipedes) and flying (e.g. Lepidoptera) invertebrates. Six lizards each contained a single millipede while one individual contained a centipede. Millipedes are avoided by numerous lizards because they are noxious (Vitt \& Cooper 1986; Wapstra \& Swain 1996), while centipedes can be venomous. We identified millipedes only to Order and have no knowledge of their noxiousness or toxicity. However, African tree agamas (Acanthocercus a. atricollis) are also known to eat millipedes (Reaney \& Whiting 2002), as do some other African lizards (Branch 1998). Either these millipedes are less noxious than their North American counterparts, or African lizards are adapted to deal with noxious prey. Field studies of velvet geckos are a necessary next step in further uncovering their unique ecology, and determining whether they really are tougher than their North American counterparts.

\section{ACKNOWLEDGEMENTS}

This study would not have been possible without the co-operation of Wulf Haacke at the Transvaal Museum, who allowed us to examine the specimens in his care. Joanne Keogh helped with all aspects of data collection and ensured that coffee breaks were kept to a minimum. For 
ongoing financial support, M.J.W. thanks the National Research Foundation and J.S.K. thanks the National Geographic Society and the Australian Research Council.

\section{REFERENCES}

BRANCH, B. 1998. Field Guide to Snakes and Other Reptiles of Southern Africa, 3rd edn. Struik Publishers, Cape Town.

FITCH, H.S. 1981. Sexual size differences in reptiles. Miscellaneous Publications of the Natural History Museum, University of Kansas 70: 1-72.

HIBBITTS, T.J., PIANKA, E.R., HUEY, R.B. \& WHITING, M.J. 2005. Ecology of the common barking gecko (Ptenopus garrulus) in southern Africa. Journal of Herpetology 39: 509-515.

OLSSON, M., SHINE, R., WAPSTRA, E., UJVARI, B. \& MADSEN, T. 2002. Sexual dimorphism in lizard body shape: the roles of sexual selection and fecundity selection. Evolution 56: 1538-1542.

PIANKA, E.R. 1986. Ecology and Natural History of Desert Lizards. Princeton University Press, Princeton, New Jersey.

PIANKA, E.R. \& VITT, L.J. 2003. Lizards: Windows to the
Evolution of Diversity. University of California Press, Berkeley, CA.

REANEY, L.T. \& WHITING, M.J. 2002. Life on a limb: ecology of the tree agama (Acanthocercus a. atricollis) in southern Africa. Journal of Zoology, London 257: 439-448.

SHINE, R. 1989. Ecological causes for the evolution of sexual dimorphism: a review of the evidence. Quarterly Review of Biology 64: 419-461.

VITT, L.J. \& COOPER, W.E. Jr 1986. Foraging and diet of a diurnal predator (Eumeces laticeps) feeding on hidden prey. Journal of Herpetology 20: 208-415.

VITT, L.J. \& ZANI, P.A. 2005. Ecology and reproduction of Anolis capito in rain forest of southeastern Nicaragua. Journal of Herpetology 39: 36-42.

VITT, L.J., ZANI, P.A., CALDWELL, J.P. \& DURTSCHE, R.D. 1993. Ecology of the whiptail lizard Cnemidophorus deppii on a tropical beach. Canadian Journal of Zoology 71: 2391-2400.

VITT, L.J., PIANKA, E.R., COOPER, W.E. Jr \& SCHWENK, K. 2003. History and the global ecology of squamate reptiles. The American Naturalist 162: 44-60.

WAPSTRA, E. \& SWAIN, R. 1996. Feeding ecology of the Tasmanian skink, Niveoscincus ocellatus (Squamata: Scincidae). Australian Journal of Zoology 44: 205-21.

Responsible Editor: P. le F. N. Mouton 